\title{
Efficiency and Mechanism of Palladium(II) Extraction from Chloride Media with $\mathrm{N}$-Hexadecylpiperidinium Chloride
}

\author{
Anna Cieszynska $^{1}{ }^{1} \cdot$ Daria Wieczorek $^{1}$
}

Received: 12 September 2019 / Accepted: 3 February 2020 / Published online: 5 May 2020

(c) The Author(s) 2020

\begin{abstract}
$\mathrm{N}$-hexadecylpiperidinium chloride ([PIP16]Cl) has been synthesized and examined as a reagent for extractive recovery of palladium(II) from hydrochloric acid solutions. The effect of the contact time between the two phases, temperature and the concentration of palladium(II) ions, the extractant and $\mathrm{HCl}$, were also evaluated. The anion-exchange mechanism of palladium(II) extraction with [PIP16]Cl was confirmed by Job's method, UV-VIS, IR and ${ }^{1} \mathrm{H}$ NMR analysis. The extraction of palladium(II) from $0.1 \mathrm{~mol} \cdot \mathrm{L}^{-1}$ $\mathrm{HCl}$ solution with [PIP16]Cl in toluene was very effective and amounted to almost $100 \%$. Increases in both $\mathrm{HCl}$ and $\mathrm{NaCl}$ concentrations and increasing temperature had negative effects on the effectiveness of palladium(II) extraction. [PIP16]Cl also exhibited selectivity to extraction of palladium(II) over some other metals: rhodium(III), iron(III), aluminium(III), copper(II) and lead(II). From among the examined stripping solutions the most effective were $0.5 \mathrm{~mol} \cdot \mathrm{L}^{-1}$ aqueous solution of ammonia and $0.1 \mathrm{~mol} \cdot \mathrm{L}^{-1}$ thiourea in 0.1 or $1 \mathrm{~mol} \cdot \mathrm{L}^{-1} \mathrm{HCl}$. The percentage of palladium(II) stripped from loaded organic phase reached nearly $100 \%$. The feasibility of regeneration of [PIP16]Cl and its reuse in subsequent extractions was also investigated.
\end{abstract}

Keywords Palladium · Extractive recovery $\cdot$ Solvent extraction $\cdot$ Stripping · $N$-hexadecylpiperidinum chloride

\section{Introduction}

Demand for precious metals such as palladium(II), platinum(IV), gold(III) and rhodium(III) is still high as they are widely used in the automotive, chemical, electrical, glass, petroleum, jewelry, medical and biomedical industries. In 2018, the global consumption of palladium was 314.7 tons, platinum 243.3 tons, gold 4,345.1 tons and rhodium 31.5 tons [1-3]. As the natural resources of these metals are limited and depleting, the effective recycling of spent materials containing these precious metals, e.g. waste electronic and electrical equipment, is required. Both pyrometallurgical and hydrometallurgical methods are

Anna Cieszynska

anna.cieszynska@ue.poznan.pl

1 Department of Technology and Instrumental Analysis, Institute of Quality Science, Poznan University of Economics and Business, al. Niepodleglosci 10, 61-875 Poznan, Poland 
used for the recovery of precious metals from natural and secondary raw materials [2-5]. Solvent extraction is one of the methods commonly used for recovery of metals from aqueous solutions. Therefore, the reagents exhibiting the ability to extract these metals have recently become a subject of interest to many researchers in the world and the synthesis of new extractants is a top priority. The choice of extractant, providing maximum efficiency of extraction requires consideration of a number of parameters, including the type of metal species, $\mathrm{pH}$ of solution and temperature. A perfect extractant should show the following characteristics $[6,7]$ :

- The ability to make a permanent chemical bond with the extracted metals in reversible reactions;

- Chemical stability and the overall solubility of the active ingredient in the free form and bound to metal, poor solubility in aqueous phase, and lack of tendency to form a third intermediate stage;

- The ability to reach the extraction equilibrium in a short time, i.e. have a high rate of extraction;

- High extraction capacity defining the maximum concentration of the metal in the organic phase;

- Low viscosity and not too low interfacial surface tension (these features allow easy mixing, rapid phase separation and lack of propensity to form emulsion);

- Low vapor pressure, non-toxicity, non-flammability, corrosive inactivity, no odor, rapid natural biodegradation, etc. (elements to ensure safe use and preserve the environment).

Classical solvent extraction has been the subject of many scientific papers. Because of increasing demand for recovered precious metals, the search for new effective precious metals extractants has gained significance. Until now many different extractants have been studied and proposed for recovery and separation of precious metals, e.g. hydrophobic amines [8-13], organophosphorus extractants [12-15], different derivatives of amides [16-21], pyridine [22, 23] and piperidine [24]. Ionic liquids are also an important group of extractants, e.g. ammonium [8, 12, 13, 25-28], phosphonium [29-33], imidazolium, pyridinium, piperidinium, pyrrolidinium [34-36] and betainium ionic liquids [37]. Looking for a fast and efficient extractant for recovery of palladium ions, we proposed to synthesize and test $N$-hexadecylpiperidinium chloride ([PIP16)]Cl). The aim of our study is to examine the extraction capabilities of the synthesized [PIP16]Cl for palladium(II) ions from hydrochloric acid solutions of various concentrations. The mechanism and thermodynamics of palladium(II) extraction have been also investigated.

\section{Experimental}

\subsection{Reagents}

Commercial palladium chloride $\mathrm{PdCl}_{2}$ (99\%, Avantor Performance Materials Poland S.A., Poland), platinum chloride $\mathrm{PtCl}_{4}$ (99\%, Avantor Performance Materials Poland S.A., Poland), rhodium chloride $\mathrm{RhCl}_{3}$ (98\%, Aldrich, Poland), gold chloride $\mathrm{AuCl}_{3}$ (99\%, Aldrich, Poland), copper chloride $\mathrm{CuCl}_{2} \cdot 2 \mathrm{H}_{2} \mathrm{O}$ (analytically pure, Chempur, Poland), lead chloride $\mathrm{PbCl}_{2}$ (analytically pure, Avantor Performance Materials Poland S.A., Poland), iron chloride $\mathrm{FeCl}_{3} \cdot 6 \mathrm{H}_{2} \mathrm{O}$ (analytically pure, Chempur, Poland), aluminum chloride 
$\mathrm{AlCl}_{3} \cdot 6 \mathrm{H}_{2} \mathrm{O}$ (analytically pure, Chempur, Poland), hydrochloric acid (analytically pure, 35-38\%, Chempur, Poland), sulfuric acid (analytically pure, 95\%, Chempur, Poland), nitric acid (analytically pure, 65\%, Avantor Performance Materials Poland S.A., Poland), ammonium thiocyanate (pure, Chempur, Poland), thiourea (analytically pure, Chempur, Poland) and aqueous ammonia (analytically pure, 25\%, Chempur, Poland) were used to prepare aqueous solutions. Toluene (analytically pure, Chempur, Poland) was used as diluent of the extractant. Piperidine (Chemat, Poland), 1-bromohexadecane (Chemat, Poland), hydrochloric acid (standard solution, Chemat, Poland) and diethyl ether (Chempur, Poland) were used for the synthesis.

\subsection{Procedure}

\subsubsection{Synthesis and Characterization of $\mathrm{N}$-Hexadecylpiperidinium Chloride}

$\mathrm{N}$-hexadecylpiperidine was obtained by the reaction described in Cieszyńska and Wieczorek [23]. Liquid $N$-hexadecylpiperidine was obtained by reacting $2 \mathrm{~mol}$ of piperidine with $1 \mathrm{~mol}$ of alkyl bromide in diethyl ether for several hours. Subsequently $(0.1 \mathrm{~mol})$ $\mathrm{N}$-hexadecylpiperidine was suspended in $15 \mathrm{~mL}$ of hot water $\left(70.0 \pm 1.0^{\circ} \mathrm{C}\right)$ while stirring. Then $(0.1 \mathrm{~mol}) 1 \mathrm{~mol} \cdot \mathrm{L}^{-1}$ hydrochloric acid was added. The reaction was carried out for $24 \mathrm{~h}$ in ambient temperature $\left(20.0 \pm 1.0{ }^{\circ} \mathrm{C}\right)$, then the solvent was evaporated (Fig. 1). Solid product was purified by recrystallization in water-ethanol (1:1). A crystalline product was filtrated in vacuum and dried in a vacuum desiccator.

The obtained $N$-hexadecylpiperidinium chloride was characterized by ${ }^{1} \mathrm{H}$ NMR and ${ }^{13} \mathrm{C}$ NMR (Varian Merkury, Gemini +300VT), IR (Jasco FT/IR-4700) and elemental analysis (Elementar Analyser Vario EL III). Melting points were determined with a DigiMelt MPA161, SRS.

The characteristics of $\mathrm{N}$-hexadecylpiperidinium chloride is given below:

${ }^{1} \mathrm{H}$ NMR $\left(\mathrm{CDCl}_{3}\right): \delta=0.74\left(\mathrm{~m}, 3 \mathrm{H}, \mathrm{CH}_{3}\right), 1.11-1.19\left(\mathrm{~m}, 26 \mathrm{H}, \mathrm{CH}_{2}\right), 1.35\left(\mathrm{~m}, 2 \mathrm{H},\left(\mathrm{CH}_{2}\right)\right.$, 1.71-1.72 (m,6H, $\left.\mathrm{CH}_{2}\right), 2.12-2.15\left(\mathrm{~m}, 2 \mathrm{H}, \mathrm{CH}_{2} \mathrm{~N}\right), 2.64-2.67\left(\mathrm{~m}, 2 \mathrm{H}, \mathrm{CH}_{2} \mathrm{~N}\right), \quad 2.81-2.85$ $\left(\mathrm{m}, 2 \mathrm{H}, \mathrm{CH}_{2} \mathrm{~N}\right), 3.35-3.38\left(\mathrm{~m}, 1 \mathrm{H}, \mathrm{NH}^{+}\right)$.

${ }^{13} \mathrm{C}$ NMR $\left(\mathrm{CDCl}_{3}\right): \delta=14.00,21.95,22.53,22.55,23.46,26.78,26.89,28.04,28.63$, 28.94, 29.22, 29.27, 29.36, 29.45, 29.51, 29.53, 29.55, 29.57, 31.79, 52.89, 57.39.

IR $=719,949,1461,2493,2848,2917 \mathrm{~cm}^{-1}$.

$2<$

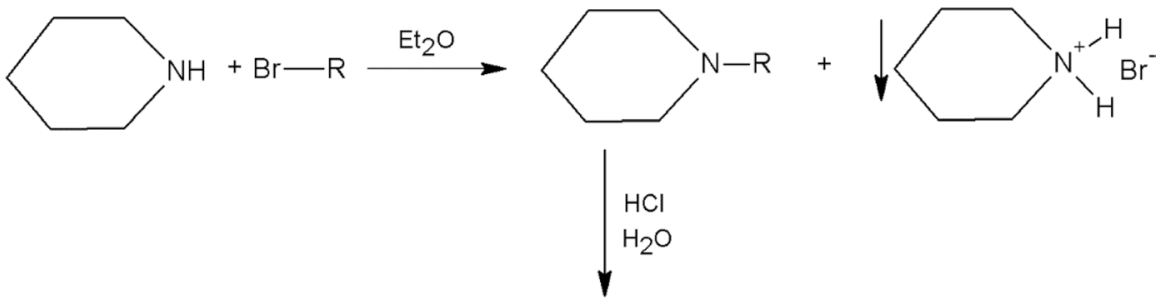

where: $\mathrm{R}=\mathrm{C}_{16} \mathrm{H}_{33}$

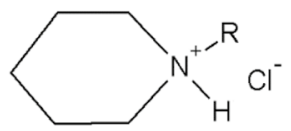

Fig. 1 Synthesis of $N$-hexadecylpiperidine chloride ([PIP16]Cl) 
Analysis calc.: C, 72.94; H, 12.74; N, 4.05 found: C, 71.52; H, 12.67; N, 3.38. mp. $=164{ }^{\circ} \mathrm{C}$, yield: $96 \%$

\subsubsection{Solvent Extraction}

Aqueous feed for single extractions contain $0.1-1 \mathrm{mmol} \cdot \mathrm{L}^{-1}$ of palladium(II) ions and the stock solutions for the selectivity experiments contain $0.5 \mathrm{mmol} \cdot \mathrm{L}^{-1}$ palladium(II) ions and $0.5 \mathrm{mmol} \cdot \mathrm{L}^{-1}$ of other metal such as rhodium(III), platinum(IV), gold(III), copper(II), lead(II), iron(III) or/and aluminum(III). Stock solutions were prepared by dissolving appropriate amounts of their suitable chlorides in double distilled water containing a minimum amount of the corresponding mineral acid. The acidity of the solution was controlled by $\mathrm{HCl}$ solutions $\left(0.1-5 \mathrm{~mol} \cdot \mathrm{L}^{-1}\right)$. Hydrochloric acid and chloride concentrations were also determined by potentiometric titration. The organic phases were $0.2-100 \mathrm{mmol} \cdot \mathrm{L}^{-1}$ solutions of [PIP16]Cl in the presence of toluene.

Both phases were mechanically shaken in glass separatory funnels and then left to stand. When both phases were clear and transparent, they were separated. Unless otherwise described, all extractions were carried out for $10 \mathrm{~min}$ at room temperature $\left(20 \pm 1.0{ }^{\circ} \mathrm{C}\right)$. The volume ratio of the aqueous phase to the organic phase was equal to $1(\mathrm{~A} / \mathrm{O}=1)$. The percentage extraction $(E)$, distribution ratio $(D)$ and separation factor $\left(S F_{\mathrm{Pd} / \mathrm{M}}\right)$ were calculated using the following equations:

$$
\begin{gathered}
E=\frac{[\mathrm{M}]_{(\mathrm{i})}-[\mathrm{M}]_{(\mathrm{aq})}^{*}}{[\mathrm{M}]_{(\mathrm{i})}} \cdot 100 \% \\
D=\frac{[\mathrm{M}]_{(\mathrm{org})}^{*}}{[\mathrm{M}]_{(\mathrm{aq})}^{*}} \\
S F_{\mathrm{Pd} / \mathrm{M}}=\frac{D_{\mathrm{Pd}}}{D_{\mathrm{M}}}
\end{gathered}
$$

where: $[\mathrm{M}]_{(\mathrm{i})}$ represents the concentration of metal ions in the aqueous phases before extraction and $[\mathrm{M}]_{(\mathrm{aq})}^{*}$ and $[\mathrm{M}]_{(\mathrm{org})}^{*}$ are the metal ion concentrations in the aqueous and organic phase after extraction.

The volumes of phases did not change. Each experiment was carried out three times and the error did not exceed 5\%.

\subsubsection{Stripping}

The loaded organic phase with palladium(II) was stripped with water, $0.1 \mathrm{~mol} \cdot \mathrm{L}^{-1}$ EDTA, $0.1 \mathrm{~mol} \cdot \mathrm{L}^{-1}$ thiourea in 0.1 or $1.0 \mathrm{~mol} \cdot \mathrm{L}^{-1} \mathrm{HCl}, 0.5 \mathrm{~mol} \cdot \mathrm{L}^{-1}$ aqueous ammonia, $0.5 \mathrm{~mol} \cdot \mathrm{L}^{-1} \mathrm{NH}_{4} \mathrm{SCN}, 5.0 \mathrm{~mol} \cdot \mathrm{L}^{-1} \mathrm{HCl}, 5 \mathrm{~mol} \cdot \mathrm{L}^{-1} \mathrm{HNO}_{3}$ and $6 \mathrm{~mol} \cdot \mathrm{L}^{-1} \mathrm{H}_{2} \mathrm{SO}_{4}(\mathrm{~A} / \mathrm{O}=1)$.

\subsubsection{Analytical Techniques}

Microwave plasma-atomic emission spectroscopy (4210 MP AES, Agilent, USA) was used for metal determination in the initial aqueous solutions and in the aqueous phases after extraction and stripping. Then the concentrations of metals in the organic phases 
were calculated based on mass balance. The organic phase loaded with palladium(II), after extraction, was separated from the aqueous phase and completely evaporated. The obtained sample of complex [PIP16]-Pd was analyzed by UV-VIS (Metertech, SP-8001 Spectrophotometer), ${ }^{1} \mathrm{H}$ NMR (Varian Mercury, Gemini +300VT) and IR using the ATR technique (Jasco FT/IR-4700).

\section{Discussion of Results}

\subsection{Effect of $\mathrm{HCl}$ and $\mathrm{NaCl}$ Concentration}

The effect of hydrochloric acid concentration and sodium chloride concentration on palladium(II) extraction with [PIP16]Cl was investigated. The increase in both $\mathrm{HCl}$ and $\mathrm{NaCl}$ concentration had an unfavorable influence on palladium(II) extraction. The extent of palladium(II) extraction from $0.1 \mathrm{~mol} \cdot \mathrm{L}^{-1} \mathrm{HCl}$ amounted to nearly $100 \%$, while from $8 \mathrm{~mol} \cdot \mathrm{L}^{-1} \mathrm{HCl}$ it decreased to approximately $10 \%$ (Fig. 2a). The increase in $\mathrm{HCl}$ concentration would favor the back reaction (Eq. 4), thus the extraction efficiency of palladium(II)

Fig. 2 Effect of $\mathrm{HCl}$ and $\mathrm{NaCl}$ concentration in the feed on the extraction of palladium(II) ions. Initial aqueous phase: (a) $[\mathrm{Pd}(\mathrm{II})]=0.5 \mathrm{mmol} \cdot \mathrm{L}^{-1}$ in $0.1-8 \mathrm{~mol} \cdot \mathrm{L}^{-1} \mathrm{HCl}$ or (b) $[\mathrm{Pd}(\mathrm{II})]=0.5 \mathrm{mmol} \cdot \mathrm{L}^{-1}$ in $0.1 \mathrm{~mol} \cdot \mathrm{L}^{-1} \mathrm{HCl}$ with $0-5 \mathrm{~mol} \cdot \mathrm{L}^{-1} \mathrm{NaCl}$; organic phase: $2 \mathrm{mmol} \cdot \mathrm{L}^{-1}$ [PIP16]Cl in toluene; $\mathrm{A} / \mathrm{O}=1$ (a)

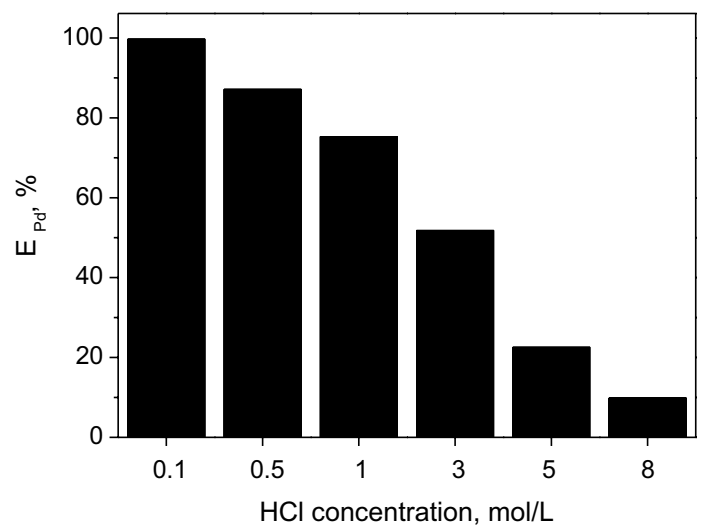

(b)

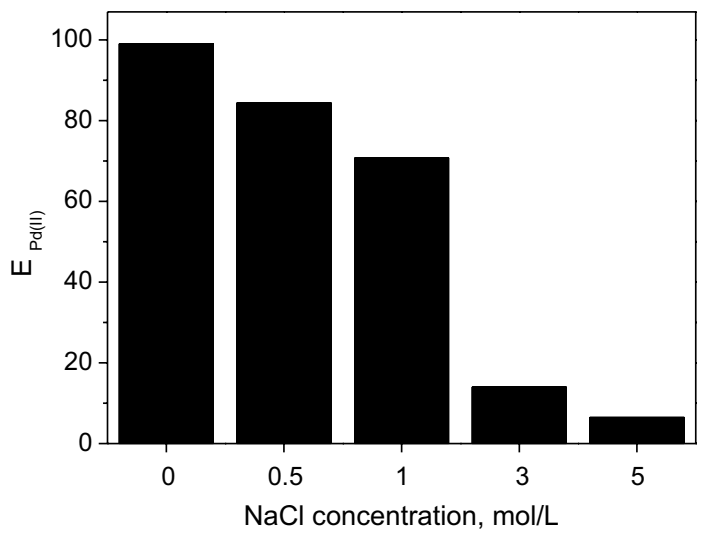


decreases. The addition of sodium chloride in the amount of 3 and $5 \mathrm{~mol} \cdot \mathrm{L}^{-1}$ caused a decrease in the percentage of palladium(II) extraction to 15 and $7 \%$, respectively (2b). The efficiency of palladium(II) extraction decreased due to competition between $\mathrm{PdCl}_{4}^{2-}$ and $\mathrm{Cl}^{-}$to bind with [PIP16] ${ }^{+}$as a result of the anion-exchange reaction [6]. The mechanism of palladium(II) extraction with $N$-hexadecylpiperidinum chloride is described in Sect. 3.3.

To verify the role of chloride ion concentration on palladium(II) extraction, the experiments of palladium(II) extraction with [PIP16]Cl were carried out at a constant $\mathrm{H}^{+}$ion concentration and $\mathrm{Cl}^{-}$ion concentrations varying in the range $0.1-5 \mathrm{~mol} \cdot \mathrm{L}^{-1}$. The concentration of chloride ion was adjusted with sodium chloride. Results are presented in Fig. 3 as plots of $\log _{10} D_{\mathrm{Pd}}$ against $\log _{10}\left[\mathrm{Cl}^{-}\right]$. The slope of this plot is equal to 3.9, which suggests that $4 \mathrm{~mol}$ of chloride ions are involved in the extraction of 1 mol of palladium(II).

\subsection{Rate of Palladium(II) Extraction}

The effect of contact time on the percentage extraction of palladium(II) with $N$-hexadecylpiperidinum chloride was investigated. The aqueous feed containing palladium(II) ions $\left(0.5 \mathrm{mmol} \cdot \mathrm{L}^{-1}\right)$ in $0.1 \mathrm{~mol} \cdot \mathrm{L}^{-1} \mathrm{HCl}$ was put in contact with $2 \mathrm{mmol} \cdot \mathrm{L}^{-1}$ [PIP16]Cl in toluene as the organic phase. The contact time was varied from 0.5 to $120 \mathrm{~min}$. The extraction of palladium(II) under these conditions was very efficient, fast and the equilibrium was achieved in 5 min (Fig. 4). Therefore, further extraction experiments were carried out for $10 \mathrm{~min}$. MathCad was used to calculate the initial rate of palladium(II) extraction from the slope at the beginning of the extraction and it amounted to $1.51 \times 10^{-5} \mathrm{~mol} \cdot \mathrm{L}^{-1} \cdot \mathrm{s}^{-1}$. Very short times (about few minutes) neccesary to achieve the extraction equilibrium are a huge advantage of reagent [PIP16]Cl in comparision with commercial dialkyl sulfides. Kinetics of palladium(II) extraction from acidic chloride solutions with these extractants is very slow and a few hours are needed to achieve equilibrium [38-40]. Pyridine derivatives like pyridinecarboxamides also extract palladium(II) very fast and efficiently. A great disadvantage of these extractants is the impossibility of palladium(II) stripping, while stripping of palladium(II) from the organic phase [PIP16]Cl is very fast and efficient.

It is worth noting that unprompted transfer of palladium(II) ions, without any shaking, to the organic phase is possible. The results obtained are presented in Fig. 5, as a linear relation between the extraction efficiency and contact time, $t^{-0.5}$, indicating that this process is

Fig. 3 Distribution ratio of palladium(II) as a function of chloride ions concentration Initial aqueous phase: $[\mathrm{Pd}(\mathrm{II})]=0.5 \mathrm{mmol} \cdot \mathrm{L}^{-1}$ in $0.1 \mathrm{~mol} \cdot \mathrm{L}^{-1} \mathrm{HCl}$ with 0-5 $\mathrm{mol} \cdot \mathrm{L}^{-1} \mathrm{NaCl}$; organic phase: $2 \mathrm{mmol} \cdot \mathrm{L}^{-1}$ [PIP16]Cl in toluene; $\mathrm{A} / \mathrm{O}=1$

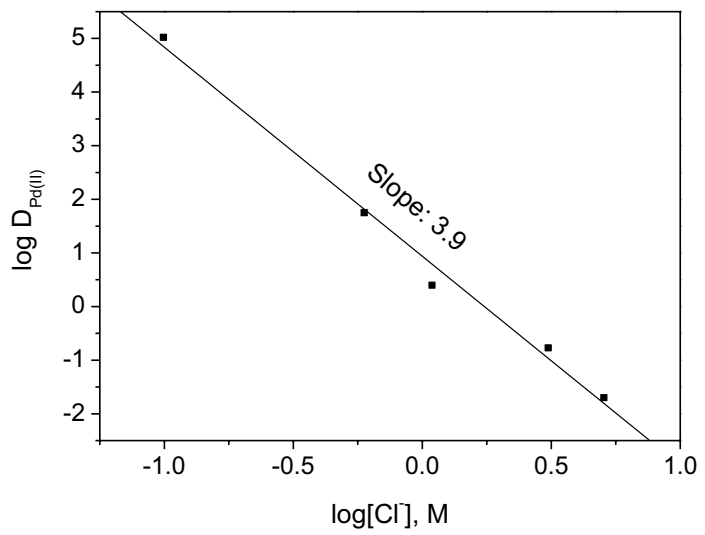


Fig. 4 Effect of contact time on ( $\square$ ) palladium(II) extraction and $(\square)$ concentration of palladium(II) in the organic phase after extraction. Initial aqueous phase: $[\mathrm{Pd}(\mathrm{II})]=0.5 \mathrm{mmol} \cdot \mathrm{L}^{-1}$ in $0.1 \mathrm{~mol} \cdot \mathrm{L}^{-1} \mathrm{HCl}$; organic phase: $2 \mathrm{mmol} \cdot \mathrm{L}^{-1}$ [PIP16]Cl in toluene; $\mathrm{A} / \mathrm{O}=1$

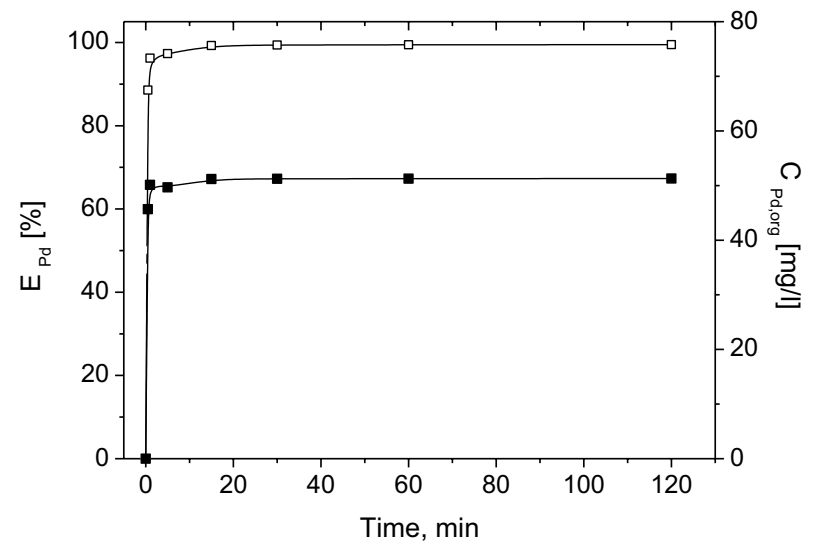

Fig. 5 Spontaneous transfer of palladium(II) ions to the organic phase. Initial aqueous phase: $[\mathrm{Pd}(\mathrm{II})]=0.5 \mathrm{mmol} \cdot \mathrm{L}^{-1}$ in $0.1 \mathrm{~mol} \cdot \mathrm{L}^{-1} \mathrm{HCl}$; organic phase: $\left.2 \mathrm{mmol} \cdot \mathrm{L}^{-1} \mathrm{PIP} 16\right] \mathrm{Cl}$ in toluene; $\mathrm{A} / \mathrm{O}=1$

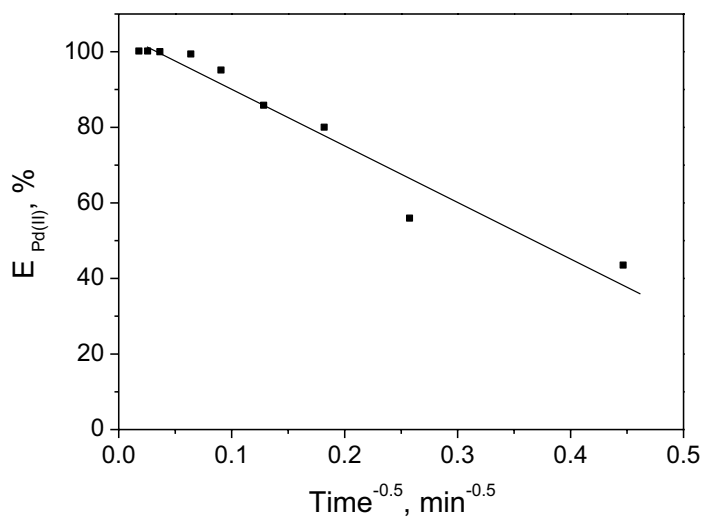

controlled by diffusion. Moreover $N$-hexadecylpiperidine chloride can additionally accelerate extraction, because it is a strong surfactant that reduces the interfacial tension.

\subsection{Mechanism of Palladium(II) Extraction}

Chlorocomplexes of palladium(II): $\mathrm{PdCl}^{+}, \mathrm{PdCl}_{2}, \mathrm{PdCl}^{3-}$ and $\mathrm{PdCl}_{4}^{2-}$ co-exist in solutions with lower concentration of chloride ions, while in chloride media of $\mathrm{Cl}^{-}$concentrations of $0.1-5 \mathrm{~mol} \cdot \mathrm{L}^{-1}$, the predominant species of palladium(II) is $\mathrm{PdCl}_{4}^{2-}[6,13,41-43]$. According to literature data, palladium(II) extraction with [PIP16]Cl should follow an anion exchange mechanism similar to that of extraction with ammonium salts. To confirm the mechanism of extraction, the nature of palladium-extractant complex was determined and spectral analysis was carried out.

\subsubsection{Determination of the Nature of the Palladium-Extractant Complex}

To confirm the mechanism of extraction, the nature of palladium-extractant complex was determined and spectral analysis was carried out. The effect of the [PIP16] $\mathrm{Cl}$ concentration on the extraction efficiency at a constant content of palladium(II) of $0.5 \mathrm{mmol} \cdot \mathrm{L}^{-1}$ was also investigated to determine the nature of extracted species 
Fig. 6 Dependence of palladium(II) distribution ratio on the extractant concentration. Initial aqueous phase: $[\mathrm{Pd}(\mathrm{II})]=0.5 \mathrm{mmol} \cdot \mathrm{L}^{-1}$ in $0.1 \mathrm{~mol} \cdot \mathrm{L}^{-1} \mathrm{HCl}$; organic phase: $0.1-100 \mathrm{mmol} \cdot \mathrm{L}^{-1}$ [PIP16]Cl in toluene; $\mathrm{A} / \mathrm{O}=1$

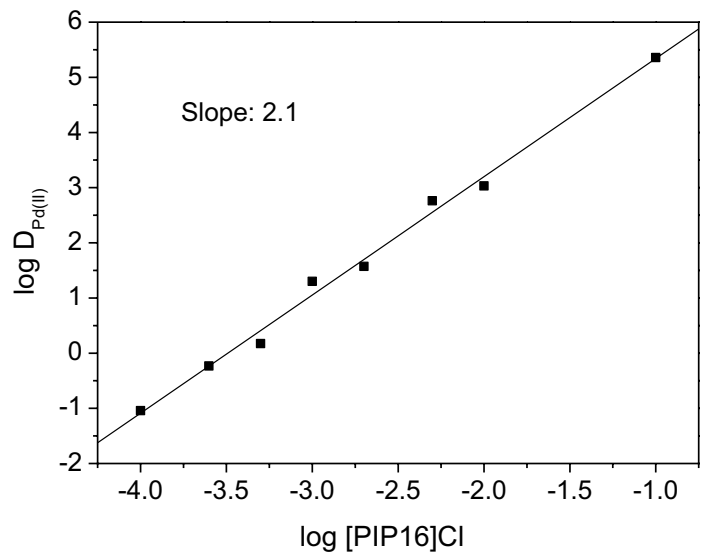

in the organic phase. Figure 6 shows the relation between the distribution ratio of palladium(II) and the concentration of extractant as a straight line of the slope of 2.1. These data suggest that two molecules of extractant take part in extraction of one molecule of palladium.

Job's method was also used to investigate the formation of complexes between $\mathrm{PdCl}_{4}^{2-}$ and [PIP16]Cl [41]. The results obtained indicate that the maximum equilibrium concentration of palladium(II) in the organic phase is achieved when the molar ratio of $\mathrm{PdCl}_{4}^{2-}$ to [PIP16]Cl is equal to 0.5 (Fig. 7). This proves that palladium(II) is extracted from $0.1 \mathrm{~mol} \cdot \mathrm{L}^{-1} \mathrm{HCl}$ to the organic phase of the molar ratio of $1: 2$, according to the following equation:

$$
\mathrm{PdCl}_{4(\mathrm{aq})}^{2-}+2[\mathrm{PIP} 16] \mathrm{Cl}_{(\mathrm{org})} \rightleftharpoons[\mathrm{PIP} 16]_{2} \mathrm{PdCl}_{4(\mathrm{org})}+2 \mathrm{Cl}_{(\mathrm{aq})}^{-}
$$

The anionic metal chlorocomplex species are extracted from the aqueous to organic phase by an anion-exchange mechanism. This mechanism is compatible with that of palladium(II) extraction with quaternary ammonium or phosphonium salts $[8,12,13$, $25,30,33$ ]. The distribution ratio $(D)$ of palladium(II) in the extraction with [PIP16]Cl can be described as follows:

Fig. 7 Job's plot for the Pd[PIP16]Cl system. The molar ratio of $\mathrm{Pd}(\mathrm{II})$ ions concentration to hexadecylpiperidine chloride concentration varies from 0.1 to $2 ; \mathrm{A} / \mathrm{O}=1$

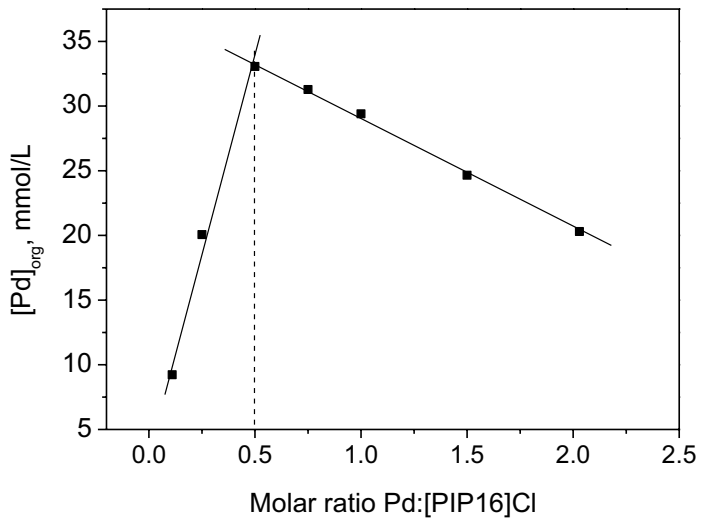


Fig. 8 UV-Vis spectra of organic phase (1) before and (2) after extraction of palladium(II). $[\mathrm{Pd}(\mathrm{II})]=0.5 \mathrm{mmol} \cdot \mathrm{L}^{-1}$ in $0.1 \mathrm{~mol} \cdot \mathrm{L}^{-1} \mathrm{HCl}$; organic phase: $2 \mathrm{mmol} \cdot \mathrm{L}^{-1}$ [PIP16]Cl in toluene; $\mathrm{A} / \mathrm{O}=1$

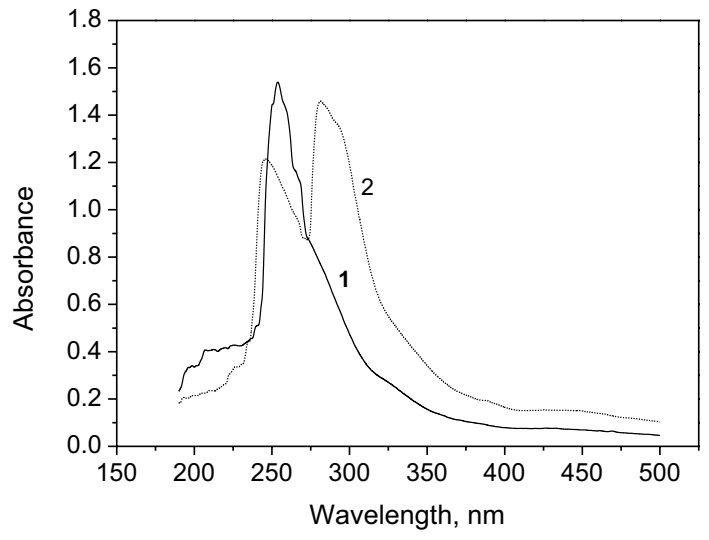

Fig. 9 Infrared spectra of [PIP16] $\mathrm{Cl}$ and $[\mathrm{PIP} 16]_{2} \mathrm{PdCl}_{4}$ complexes

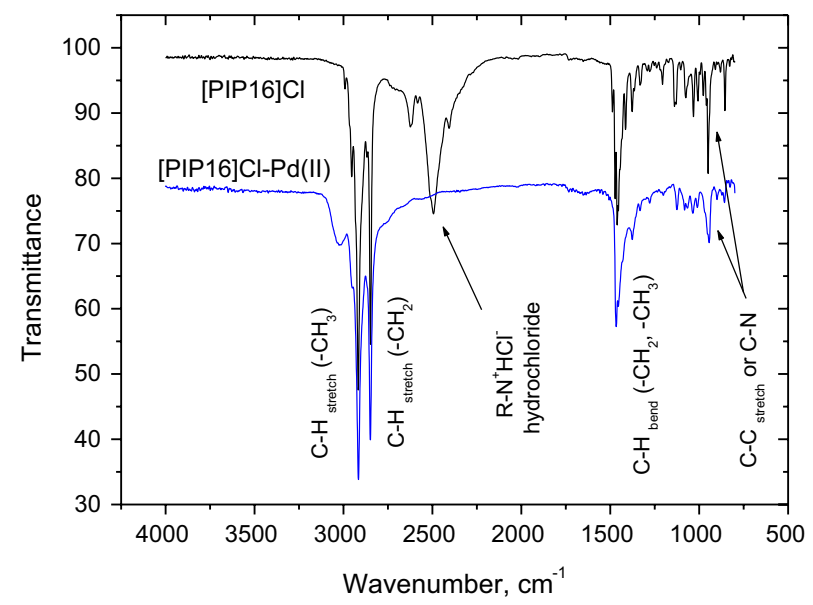

$$
D=\frac{[\mathrm{Pd}]_{(\mathrm{org})}}{[\mathrm{Pd}]_{(\mathrm{aq})}}=\frac{\left[[\mathrm{PIP} 16]_{2} \mathrm{PdCl}_{4}\right]_{(\mathrm{org})}}{\left[\mathrm{PdCl}_{4}^{2-}\right]_{(\mathrm{aq})}}
$$

\subsubsection{Spectrophotometric Analysis of the Palladium-Extractant Complex}

The organic phases before and after extraction of palladium(II) from $0.1 \mathrm{~mol} \cdot \mathrm{L}^{-1} \mathrm{HCl}$ were subjected to UV-Vis analysis in the wavelength range $190-500 \mathrm{~nm}$. Toluene was used as a reference. As shown in Fig. 8, the spectra of organic phases before and after extraction differ. Before extraction, the spectrum of the organic phase shows one ultraviolet absorption peak at $250 \mathrm{~nm}$, while after the extraction its spectrum shows two peaks at 246 and $281 \mathrm{~nm}$. These results suggest that the peak near $250 \mathrm{~nm}$ corresponds to [PIP16]Cl, while that at 281 corresponds to [PIP16 $]_{2} \mathrm{PdCl}_{4}$.

The IR spectra of organic phase before and after extraction are presented in Fig. 9. The bands assigned to stretching vibrations appear at 2848, 2916, and $2992 \mathrm{~cm}^{-1}$, so in the same region, and are assigned to the stretching modes of $\mathrm{C}-\mathrm{H}$. The band corresponding to the stretching vibrations of the $\mathrm{NH}^{+}$group can be observed at $2494 \mathrm{~cm}^{-1}$. 
This band is not present in the spectra recorded after extraction. It is assigned to the protons in the closest neighborhood of the nitrogen donor, therefore, its disappearance indicates that the metals interact with the nitrogen donor. The band at $1460 \mathrm{~cm}^{-1}$ is the bending mode of $\mathrm{C}-\mathrm{H}$ and can be seen on both spectra with no shift. The band at $949 \mathrm{~cm}^{-1}$ present in the spectra recorded before and after extraction, corresponds to the stretching modes of $\mathrm{C}-\mathrm{N}$.

The NMR chemical shifts before and after extraction of palladium(II) from $0.1 \mathrm{~mol} \cdot \mathrm{L}^{-1} \mathrm{HCl}$ were examined to study the position of bonding between the metal and the extractant. The NMR spectra are presented in Fig. 10.

The the NMR peaks at 0.74 and $1.1-1.35 \mathrm{ppm}$ were shifted toward lower magnetic field by $0.15 \mathrm{ppm}$ after the extractions. The peak assigned to the protons of piperidine ring $(1.71 \mathrm{ppm})$ was shifted to a lower magnetic field (by $0.25 \mathrm{ppm}$ ) after the palladium loading, which is in agreement with the observation made by Yamaguma et al. concerning the extraction of silver by pyridyl derivative extractant [44]. More significant changes in chemical shifts are observed for the peaks assigned to the protons in the closest neighborhood of the $\mathrm{N}$ atom, namely those at $2.15,2.64,2.81,3.35 \mathrm{ppm}$. After extraction, the peaks were shifted to $2.41,2.79,3.15$ and $3.68 \mathrm{ppm}$, respectively. Thus, the changes in the peaks corresponding to the protons neighboring the donor atom include not only their shifts but also deformation of their shapes. Similar observation has been reported by Sasaki et al. who showed that the shifts of the peaks depend on the type of metal extracted. Moreover, the deformation of peak shape is likely due to the paramagnetization of $\mathrm{Pd}(\mathrm{II})[21]$.

Fig. $10{ }^{1} \mathrm{H}$ NMR spectra of (a) [PIP16]Cl and (b) [PIP16] ${ }_{2} \mathrm{PdCl}_{4}$ complex
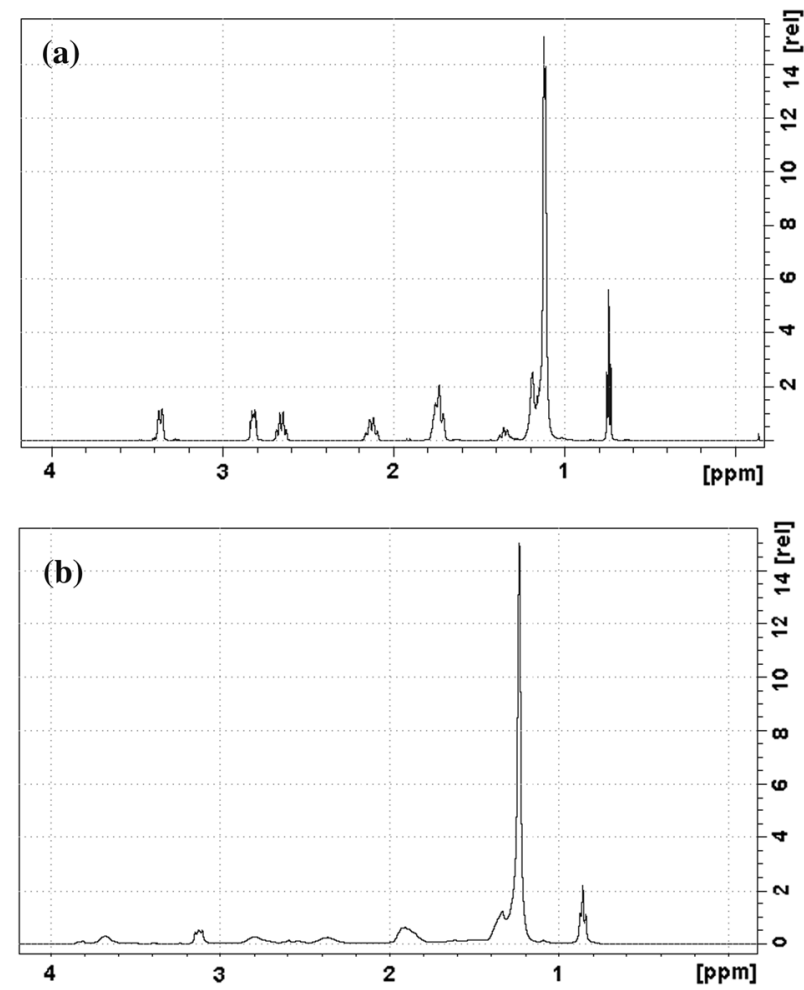


\subsubsection{Effect of Temperature}

The effect of temperature in the range $20-70{ }^{\circ} \mathrm{C}$ on palladium(II) extraction from $0.1 \mathrm{~mol} \cdot \mathrm{L}^{-1} \mathrm{HCl}$ was investigated (Fig. 11). The extraction equilibrium constant and thermodynamic parameters were also determined. Increase in temperature causes a negligible decrease in the palladium(II) distribution ratio. According to the equations of extraction mechanism and distribution ratio (Sect. 3.3.1), the extraction constants $\left(\log _{10} K_{\mathrm{ex}}\right)$ were estimated using the experimental data and the following equations [45]:

$$
\begin{gathered}
K_{\mathrm{ex}}=\frac{\left[[\mathrm{PIP} 16]_{2} \mathrm{PdCl}_{4}\right]_{(\mathrm{org})} \cdot\left[\mathrm{Cl}^{-}\right]_{(\mathrm{aq})}^{2}}{\left[\mathrm{PdCl}_{4}^{2-}\right]_{(\mathrm{aq})} \cdot[[\mathrm{PIP} 16] \mathrm{Cl}]_{(\mathrm{org})}^{2}} \\
K_{\mathrm{ex}}=D \cdot \frac{\left[\mathrm{Cl}^{-}\right]_{(\mathrm{aq})}^{2}}{[[\mathrm{PIP} 16] \mathrm{Cl}]_{(\mathrm{org})}^{2}} \\
\log _{10} K_{\mathrm{ex}}=\log _{10} D+2 \log _{10}\left[\mathrm{Cl}^{-}\right]_{(\mathrm{aq})}-2 \log _{10}[[\mathrm{PIP} 16] \mathrm{Cl}]_{(\mathrm{org})}
\end{gathered}
$$

The values of enthalpies $\Delta H^{\circ}$ and entropies $\Delta S^{\circ}$ were calculated using the Gibbs-Helmholtz equation:

$$
\log _{10} K_{\mathrm{ex}}=\frac{-\Delta H^{\circ}}{2.303 R T}+\frac{\Delta S^{\circ}}{2.303 R}
$$

The standard enthalpy $\Delta H^{\circ}$ is determined from the slope of the line $\log _{10} K_{\text {ex }}$ against $T^{-1}$, while the standard entropy $\Delta S^{\circ}$ of the extraction is the coordinate of the intersection point of the plot shown in Fig. 11 with the coordinate axis. The Gibbs energy $\Delta G^{\circ}=\Delta H^{\circ}-T \Delta S^{\circ}$ was also calculated. The values of $\log _{10} K_{\mathrm{ex}}, \Delta H^{\circ}, \Delta S^{\circ}$ and $\Delta G^{\circ}$ are listed in Table 1. The results obtained indicate that the extraction of palladium(II) with $\mathrm{N}$-hexadecylpiperidinium chloride in toluene is an exothermic reaction.

\subsection{Stripping of Palladium(II) from the Loaded Organic Phase}

Stripping palladium(II) from the loaded organic phase after extraction from $0.1 \mathrm{~mol} \cdot \mathrm{L}^{-1}$ $\mathrm{HCl}$ with [PIP16] Cl in toluene was examined. Different stripping solutions: water,

Fig. 11 The effect of temperature on the logarithm of palladium(II) extraction constants. Initial aqueous phase: $[\mathrm{Pd}(\mathrm{II})]=0.5 \mathrm{mmol} \cdot \mathrm{L}^{-1}$ in $0.1 \mathrm{~mol} \cdot \mathrm{L}^{-1} \mathrm{HCl}$; the organic phase: $2 \mathrm{mmol} \cdot \mathrm{L}^{-1}$ [PIP16]Cl in toluene; $\mathrm{A} / \mathrm{O}=1$

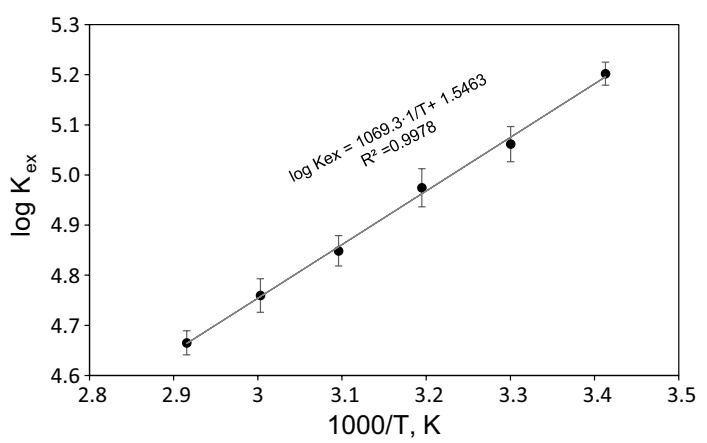


Table 1 The values of extraction constant $\log _{10} K_{\mathrm{ex}}$ and thermodynamic parameters: $\Delta H^{\circ}, \Delta S^{\circ}$ and $\Delta G^{\circ}$ of palladium(II) extraction

\begin{tabular}{lllll}
\hline$T[\mathrm{~K}]$ & $\log _{10} K_{\mathrm{ex}}$ & $\Delta H^{\circ}\left[\mathrm{kJ} \cdot \mathrm{mol}^{-1}\right]$ & $T \Delta S^{\circ}\left[\mathrm{kJ} \cdot \mathrm{mol}^{-1}\right]$ & $\Delta G^{\circ}\left[\mathrm{kJ} \cdot \mathrm{mol}^{-1}\right]$ \\
\hline 293 & 5.2 & -20.5 & 8.7 & -29.1 \\
303 & 5.1 & & 9.0 & -29.4 \\
313 & 5.0 & & 9.3 & -29.7 \\
323 & 4.9 & 9.6 & -30.0 \\
333 & 4.8 & & 9.9 & -30.3 \\
343 & 4.7 & & 10.2 & -30.6 \\
\hline
\end{tabular}

Initial aqueous phase: $[\mathrm{Pd}(\mathrm{II})]=0.5 \mathrm{mmol} \cdot \mathrm{L}^{-1}$ in $0.1 \mathrm{~mol} \cdot \mathrm{L}^{-1} \mathrm{HCl}$; the organic phase: $2 \mathrm{mmol} \cdot \mathrm{L}^{-1}$ [PIP16] $\mathrm{Cl}$ in toluene; $\mathrm{A} / \mathrm{O}=1$

$0.1 \mathrm{~mol} \cdot \mathrm{L}^{-1}$ EDTA, $0.5 \mathrm{~mol} \cdot \mathrm{L}^{-1}$ aqueous ammonia, $0.5 \mathrm{~mol} \cdot \mathrm{L}^{-1} \mathrm{NH}_{4} \mathrm{SCN}, 6 \mathrm{~mol} \cdot \mathrm{L}^{-1}$ $\mathrm{H}_{2} \mathrm{SO}_{4}, 5 \mathrm{~mol} \cdot \mathrm{L}^{-1} \mathrm{HNO}_{3}, 5 \mathrm{~mol} \cdot \mathrm{L}^{-1} \mathrm{HCl}$ and $0.1 \mathrm{~mol} \cdot \mathrm{L}^{-1}$ thiourea in 0.1 or $1 \mathrm{~mol} \cdot \mathrm{L}^{-1}$ $\mathrm{HCl}$ were used. The stripping was carried out in two stages and the results are presented in Fig. 12. The stripping with water and $6 \mathrm{~mol} \cdot \mathrm{L}^{-1} \mathrm{H}_{2} \mathrm{SO}_{4}$ is ineffective and the efficiency amounts to 0.4 and $5.5 \%$, respectively, in two stages. Better results were achieved using $5 \mathrm{~mol} \cdot \mathrm{L}^{-1} \mathrm{HNO}_{3}$ and $5 \mathrm{~mol} \cdot \mathrm{L}^{-1} \mathrm{HCl}$ and the percentage of stripping in two stages reached 52 and $59 \%$, respectively. The stripping with $0.1 \mathrm{~mol} \cdot \mathrm{L}^{-1}$ EDTA was $60 \%$ and with $0.5 \mathrm{~mol} \cdot \mathrm{L}^{-1} \mathrm{NH}_{4} \mathrm{SCN}$ was near $90 \%$, wherein the first step of stripping was much more efficient than the second. The best results were achieved for stripping with $0.5 \mathrm{~mol} \cdot \mathrm{L}^{-1}$ aqueous ammonia and $0.1 \mathrm{~mol} \cdot \mathrm{L}^{-1}$ thiourea in 0.1 or $1 \mathrm{~mol} \cdot \mathrm{L}^{-1} \mathrm{HCl}$. Palladium(II) ions were transferred in the first stage from the organic phase to all aqueous solutions in $100 \%$.

\subsection{Regeneration of the Organic Phase}

The regeneration of a spent organic phase is perfectly legitimate, not only because of the impact that the waste organic solutions may have on the environment, but also it is

Fig. 12 Stripping of palladium(II) in ( $\mathbf{\square})$ first stage and ( $\mathbf{\square})$ second stage from loaded organic phase containing $\mathrm{Pd}$ (II) in $2 \mathrm{mmol} \cdot \mathrm{L}^{-1}$ [PIP16] $\mathrm{Cl}$ after extraction; $\mathrm{A} / \mathrm{O}=1(\mathrm{M}$ denotes concentration in units of $\mathrm{mol} \cdot \mathrm{L}^{-1}$ )

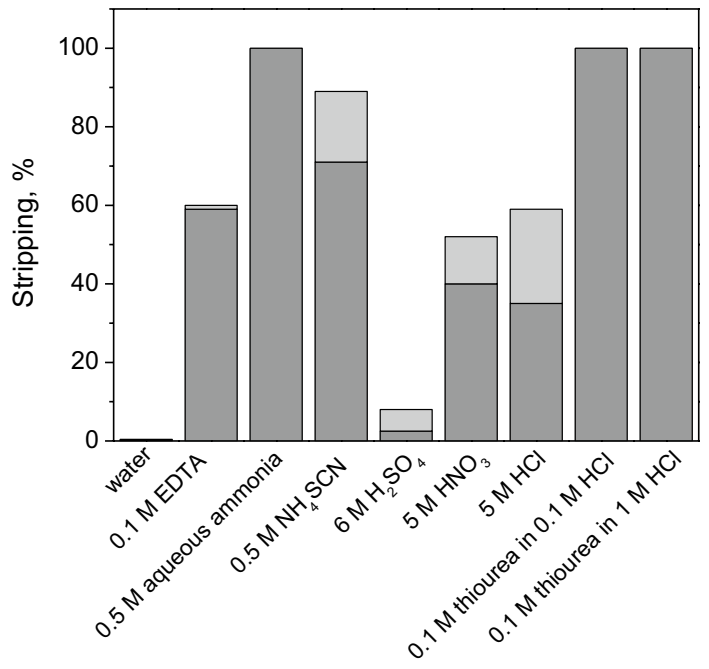


economically motivated as it offers the possibility of reusing the organic reagents in subsequent palladium(II) extractions. After extraction of palladium(II) from $0.1 \mathrm{~mol} \cdot \mathrm{L}^{-1}$ $\mathrm{HCl}$ with fresh $2 \mathrm{mmol} \cdot \mathrm{L}^{-1}$ [PIP16]Cl, the loaded organic phase was stripped twice with $0.5 \mathrm{~mol} \cdot \mathrm{L}^{-1}$ aqueous ammonia or $0.1 \mathrm{~mol} \cdot \mathrm{L}^{-1}$ thiourea in $0.1 \mathrm{~mol} \cdot \mathrm{L}^{-1} \mathrm{HCl}$ to ensure complete removal of palladium(II) ions. Then the organic phases were regenerated with deionized water and $5 \mathrm{~mol} \cdot \mathrm{L}^{-1} \mathrm{HCl}$ and were used again for extraction. This procedure of extraction-stripping-regeneration was repeated six times.

Efficiencies of palladium(II) extraction from $0.1 \mathrm{~mol} \cdot \mathrm{L}^{-1} \mathrm{HCl}$ with both fresh and regenerated extractant are comparable and amount to almost $100 \%$ (Fig. 13). It means that $\mathrm{N}$-hexadecylpiperidinium chloride is a stable extractant that can be reused for extraction of palladium(II), because regeneration does not change its extractive properties.

\subsection{Separation of Palladium(II) from other Metals}

Recently, separation of palladium(II), gold(III), rhodium(III) and platinum(IV) from chloride solution has been examined by many researchers [13, 16, 21, 32, 36]. The recovery and separation of palladium(II) e.g. from electronic scraps containing other metals may be processed using the extraction-stripping procedure. Therefore, the possibility of selective extraction of palladium(II) over one chosen metal: platinum(IV), rhodium(III), gold(III), aluminium(III), iron(III), copper(II) and lead(II) was investigated. The results presented in Table 2 indicate that the best palladium(II) separation was observed in the presence of rhodium(III), aluminum(III), iron(III), copper(II) and lead(II). The extraction of palladium(II) amounts to 98-99\%, while the extraction efficiency of rhodium(III), aluminum(III), iron(III), copper(II) and lead(II) does not exceed 7\%. Separation of palladium(II) from platinum(IV) and gold(III) from $0.1 \mathrm{~mol} \cdot \mathrm{L}^{-1} \mathrm{HCl}$ by extraction with [PIP16]Cl is not possible. The results show that the extraction ability of [PIP16]Cl towards palladium(II), platinum(IV) and gold(III) was similar for two-metal solutions.

Extraction of palladium(II) from multi-metal solutions was also studied. The results obtained indicate that in multi-metal system the extraction capacity of [PIP16]Cl towards the tested precious metals from $0.1 \mathrm{~mol} \cdot \mathrm{L}^{-1} \mathrm{HCl}$ is $\operatorname{gold}(\mathrm{III})>$ palladium(II) $>$ platinum(IV) $>>$ rhodium(III) (Fig. 14). Separation of palladium(II), platinum(IV) and gold(III),

(a)

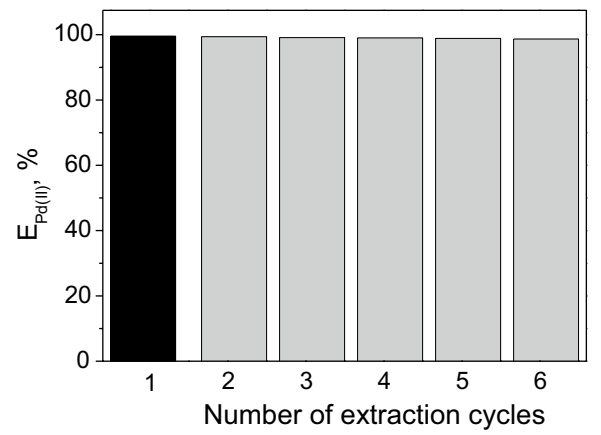

(b)

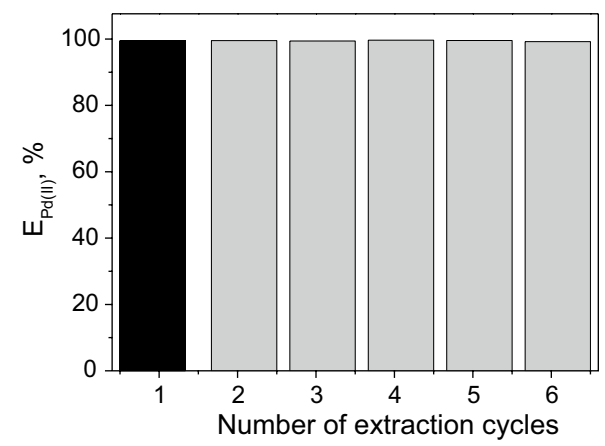

Fig. 13 Extraction of palladium(II) with fresh ( $\square$ ) and regenerated ( $\square$ ) [PIP16]Cl after stripping with a) $0.5 \mathrm{~mol} \cdot \mathrm{L}^{-1}$ aqueous ammonia and b) $0.1 \mathrm{~mol} \cdot \mathrm{L}^{-1}$ thiourea in $0.1 \mathrm{~mol} \cdot \mathrm{L}^{-1} \mathrm{HCl}$. Initial aqueous phase: $[\mathrm{Pd}(\mathrm{II})]=0.5 \mathrm{mmol} \cdot \mathrm{L}^{-1}$ in $0.1 \mathrm{~mol} \cdot \mathrm{L}^{-1} \mathrm{HCl}$; organic phase: $2 \mathrm{mmol} \cdot \mathrm{L}^{-1}$ [PIP16]Cl in toluene; $\mathrm{A} / \mathrm{O}=1$ 
Table 2 Extraction and separation of palladium(II) from two-metal solutions

\begin{tabular}{llll}
\hline Feed & $E_{\mathrm{Pd}}\left(E_{\mathrm{Met}}\right), \%$ & $D_{\mathrm{Pd}}\left(D_{\mathrm{Met}}\right)$ & $S F_{\mathrm{Pd} / \mathrm{Met}}$ \\
\hline $\mathrm{Pd}(\mathrm{II})-\mathrm{Pt}(\mathrm{IV})$ & $94.5(83.6)$ & $17.2(5.10)$ & 3.38 \\
$\mathrm{Pd}(\mathrm{II})-\mathrm{Au}(\mathrm{III})$ & $97.0(99.4)$ & $32.7(160.3)$ & 0.204 \\
$\mathrm{Pd}(\mathrm{II})-\mathrm{Rh}(\mathrm{III})$ & $98.7(6.5)$ & $74.9(0.07)$ & 1070 \\
$\mathrm{Pd}(\mathrm{II})-\mathrm{Al}(\mathrm{III})$ & $99.5(3.5)$ & $209(0.036)$ & 5728 \\
$\mathrm{Pd}(\mathrm{II})-\mathrm{Fe}(\mathrm{III})$ & $99.4(3.9)$ & $167(0.04)$ & 4146 \\
$\mathrm{Pd}(\mathrm{II})-\mathrm{Cu}(\mathrm{II})$ & $99.6(2.8)$ & $237(0.029)$ & 8094 \\
$\mathrm{Pd}(\mathrm{II})-\mathrm{Pb}(\mathrm{II})$ & $97.8(1.7)$ & $45.2(0.017)$ & 2659 \\
\hline
\end{tabular}

Initial aqueous phase: $[\mathrm{Pd}(\mathrm{II})]=0.5 \mathrm{mmol} \cdot \mathrm{L}^{-1}[\mathrm{metal}]=0.5 \mathrm{mmol} \cdot \mathrm{L}^{-1}$ in $0.1 \mathrm{~mol} \cdot \mathrm{L}^{-1} \mathrm{HCl}$; organic phase: $2 \mathrm{mmol} \cdot \mathrm{L}^{-1}$ [PIP16]Cl in toluene; $\mathrm{A} / \mathrm{O}=1$
Fig. 14 Extraction of palladium(II), platinum(IV), gold(III), rhodium(III), aluminum(III), iron(III), copper(II) and lead(II) from multi-metal solution. Initial aqueous phase: $[$ metal $]=0.5 \mathrm{mmol} \cdot \mathrm{L}^{-1}$ in $0.1 \mathrm{~mol} \cdot \mathrm{L}^{-1} \mathrm{HCl}$; organic phase: (ロ) $2 \mathrm{mmol} \cdot \mathrm{L}^{-1}$ and (ロ) $10 \mathrm{mmol} \cdot \mathrm{L}^{-1}[\mathrm{PIP} 16] \mathrm{Cl}$ in toluene; $\mathrm{A} / \mathrm{O}=1$

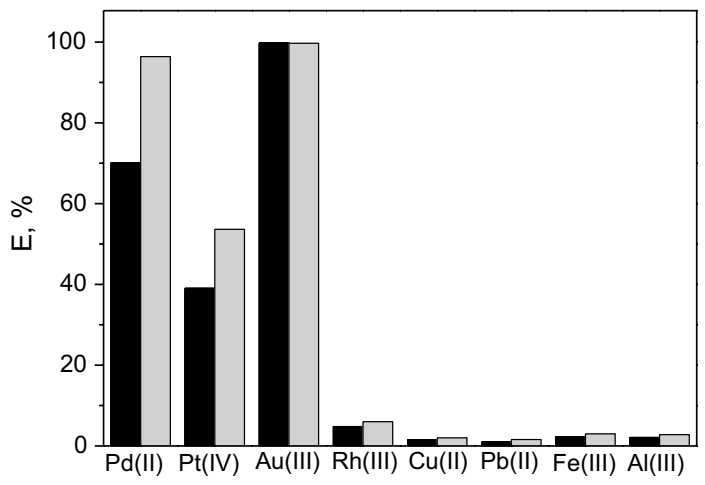

which is not possible by extraction, is possible using the stripping process (Table 3). The palladium(II), platinum(IV) and gold(III) were successfully separated and recovered with $0.5 \mathrm{~mol} \cdot \mathrm{L}^{-1}$ aqueous ammonia (Stripping I), $5 \mathrm{~mol} \cdot \mathrm{L}^{-1} \mathrm{HNO}_{3}$ (Stripping II) and $0.1 \mathrm{~mol} \cdot \mathrm{L}^{-1}$ thiourea in $0.1 \mathrm{~mol} \cdot \mathrm{L}^{-1} \mathrm{HCl}$ (Stripping III), respectively.

\section{Conclusions}

$\mathrm{N}$-hexadecylpiperidinum chloride in toluene was examined for palladium(II) extraction from hydrochloric acid solutions. The extraction of palladium(II) from chloride media is effective, fast and depends upon $\mathrm{HCl}$ and $\mathrm{NaCl}$ concentrations, extractant concentration, contact time of the phases and temperature of extraction. The efficient extraction of palladium(II) from $0.1 \mathrm{~mol} \cdot \mathrm{L}^{-1} \mathrm{HCl}$ solution with [PIP16]Cl in toluene amounts to almost $100 \%$. The anion-exchange mechanism of palladium(II) extraction with [PIP16]Cl was confirmed by Job's method, UV-VIS, IR and ${ }^{1} \mathrm{H}$ NMR analysis, and palladium(II) was extracted to the organic phase as $[\mathrm{PIP} 16]_{2} \mathrm{PdCl}_{4}$. The thermodynamic parameters of the reaction were obtained and indicate that extraction of palladium(II) from $0.1 \mathrm{~mol} \cdot \mathrm{L}^{-1}$ $\mathrm{HCl}$ with [PIP16]Cl in toluene is an exothermic reaction. The extractant studied [PIP16] $\mathrm{Cl}$ can be reused at least in 6 cycles of extraction-stripping-regeneration process 


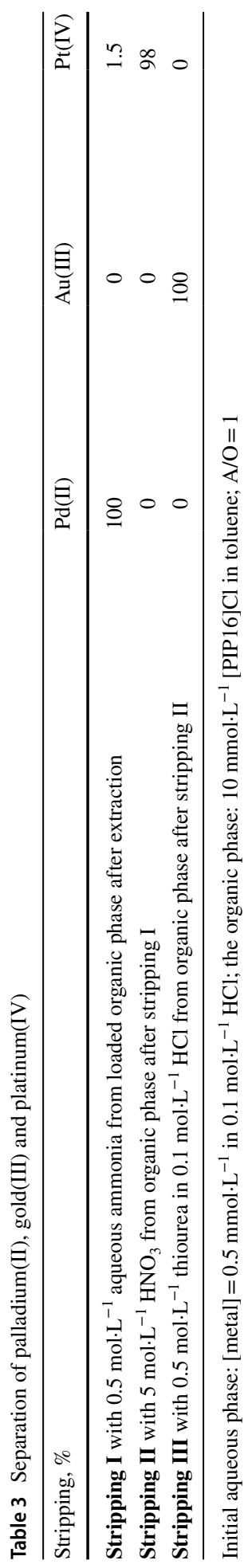


without a significant loss in the extraction power. Separation and recovery of palladium(II), platinum(IV) and gold(III) is possible using the extraction-stripping process.

Acknowledgements This work was supported by the grant of the National Science Centre number 2017/01/X/ST5/01565.

Open Access This article is licensed under a Creative Commons Attribution 4.0 International License, which permits use, sharing, adaptation, distribution and reproduction in any medium or format, as long as you give appropriate credit to the original author(s) and the source, provide a link to the Creative Commons licence, and indicate if changes were made. The images or other third party material in this article are included in the article's Creative Commons licence, unless indicated otherwise in a credit line to the material. If material is not included in the article's Creative Commons licence and your intended use is not permitted by statutory regulation or exceeds the permitted use, you will need to obtain permission directly from the copyright holder. To view a copy of this licence, visit http://creativecommons.org/licenses/by/4.0/.

\section{References}

1. Statista. https://www.statista.com. Accessed 5 January 2020

2. Matthey J.: PGM Market Reports February 2019. https://www.platinum.matthey.com. Accessed 30 May 2019

3. World Gold Council. https://www.gold.org. Accessed 30 May 2019

4. Hagelüken, C.: Recycling of electronic scrap at Umicore's integrated metals smelter and refinery. World Metall Erzmetall 59(3), 152-161 (2006)

5. Hagelüken, C., Corti, C.W.: Recycling of gold from electronics: cost-effective use through 'Design for Recycling'. Gold Bull. 43(3), 209-220 (2010)

6. Bernardis, F.L., Grant, R.A., Sherrington, D.C.: A review of methods of separation of the platinum-group metals through their chloro-complexes. React. Funct. Polym. 65, 205-217 (2005)

7. Thornton, J.D., Cox, M.: Science and Practice of Liquid-Liquid Extraction. Clarendon Press, Oxford (1992)

8. Jha, M.K., Gupta, D., Lee, J.-C., Kumar, V., Jeong, J.: Solvent extraction of platinum using amine based extractants in different solutions: a review. Hydrometallurgy 142, 60-69 (2014)

9. Lee, J.Y., Kumar, J.R., Kim, J.S., Park, H.K., Yoon, H.S.: Liquid-liquid extraction/separation of platinum(IV) and rhodium(III) from acidic chloride solutions using tri-iso-octylamine. J. Hazard. Mater. 168, 424-429 (2009)

10. Najafi, A., Kargari, A., Soleimani, M.: Extraction of palladium from aqueous wastewaters using Alamine 300 as extractant. Desalin. Water Treat. 53, 2177-2183 (2015)

11. Swain, B., Jeong, J., Kim, S., Lee, J.: Separation of platinum and palladium from chloride solution by solvent extraction using Alamine 300. Hydrometallurgy 104, 1-7 (2010)

12. Nguyen, T.H., Sonu, C.H., Lee, M.S.: Separation of platinum(IV) and palladium(II) from concentrated hydrochloric acid solutions by mixtures of amines with neutral extractants. J. Ind. Eng. Chem. 32, 238245 (2015)

13. Nguyen, T.H., Sonu, C.H., Lee, M.S.: Separation of Pt(IV), Rh(III) and Ir(III) from concentrated hydrochloric acid solutions by solvent extraction. Hydrometallurgy 164, 71-77 (2016)

14. Gupta, B., Singh, I.: Extraction and separation of palladium and rhodium using Cyanex 923 and their recovery from real samples. Hydrometallurgy 134-135, 11-18 (2013)

15. Gupta, B., Singh, I., Mahandra, H.: Extraction and separation studies on Pt(IV), Ir(III) and Rh(III) using sulphur containing extractant. Sep. Purif. Technol. 132, 102-109 (2014)

16. Costa, M.C., Assuncao, A., Almeida, R., da Costa, A.M.R., Nogueira, C., Paiva, A.P.: $N$, $N$ '-dimethyl- $N$, $N$ '-dicyclohexylsuccinamide: a novel molecule for the separation and recovery of $\mathrm{Pd}(\mathrm{II})$ by liquid-liquid extraction. Sep. Purif. Technol. 201, 96-105 (2018)

17. Huang, H., Huang, C., Wu, X., Ding, S., Liu, N., Su, D., Lv, T.: Extraction of palladium(II) from nitric acid solutions with diglycolthioamide. Hydrometallurgy 156, 6-11 (2015)

18. Mowafy, E.A., Mohamed, D.: Extraction and separation of gold(III) from hydrochloric acid solutions using long chain structurally tailored monoamides. Sep. Purif. Technol. 167, 146-153 (2016)

19. Ortet, O., Paiva, A.P.: Development of tertiary thioamide derivatives to recovery palladium(II) from simulated complex chloride solutions. Hydrometallurgy 151, 33-41 (2015)

20. Paiva, A.P., Carvalho, G.I., Costa, M.C., da Costa, A.M.R., Nogueira, C.: N'-dimethyl-N,N'-dibutylmalonamide towards platinum and palladium in chloride media. Sep. Sci. Technol. 49, 966-973 (2014) 
21. Sasaki, Y., Morita, K., Morihisa, S., Hisamatsu, S., Yoshizuka, K.: Presious metal extraction by N,N,N',N'-tetraoctyl-thiodiglycolamide and its comparision with N,N,N',N'-tetraoctyl-diglycolamide and methylimino-N,N'-dioctylacetamide. Hydrometallurgy 169, 576-584 (2017)

22. Khogare, B.T., Anuse, M.A., Piste, P.B., Kokare, B.N.: Development of a solvent extraction system with 4-heptylaminopyridine for the selective separation of palladium(II) from synthetic mixture, catalysts and water samples. Desalin. Water. Treat. 57, 21634-21644 (2016)

23. Khogare, B.T., Kamblec, G.S., Kokarec, A.N., Zanjec, S.B., Suryavanshic, V.J., Anuse, M.A., Piste, P.B., Kokare, B.N.: Development of novel solvent extraction method for determination of gold(III) using 4-heptylaminopyridine: application to alloys and environmental analysis. J. Environ. Chem. Eng. 4, 3075-3083 (2016)

24. Cieszynska, A., Wieczorek, D.: Extraction and separation of palladium(II), platinum(IV), gold(III) and rhodium(III) using piperidine-based extractants. Hydrometallurgy 175, 359-366 (2018)

25. Belova, V.V., Khol'kin, A.I., Zhidkova, T.I.: Extraction of platinum-group metals from chloride solutions by salts of quaternary ammonium bases and binary extractants. Theor. Found. Chem. Eng. 41, 743-751 (2007)

26. Lee, J.Y., Kumar, J.R., Kim, J.S., Kim, D.J., Yoon, H.S.: Extraction and separation of Pt(IV)/Rh(III) from acidic chloride solutions using Aliquat 336. J. Eng. Chem. 15, 359-364 (2009)

27. Giridhar, P., Venkastesan, K.A., Srinivasan, K.A., Vasudeva, R.P.R.: Extraction of fission palladium by Aliquat 336 and electrochemical studies on direct recovery from ionic liquid phase. Hydrometallurgy 81, 30-39 (2006)

28. Raju, B., Kumar, J.R., Lee, J.Y., Kwon, H.S., Kantran, M.L., Reddy, B.R.: Separation of platinum and rhodium from chloride solutions containing aluminium, magnesium and iron using solvent extraction and precipitation methods. J. Hazard. Mater. 227-228, 142-147 (2012)

29. Cieszynska, A., Wisniewski, M.: Selective extraction of palladium(II) from hydrochloric acid solutions with phosphonium extractants. Sep. Purif. Technol. 2, 385-389 (2011)

30. Cieszynska, A., Wisniewski, M.: Extractive recovery of palladium(II) from hydrochloric acid solutions with Cyphos IL 104. Hydrometallurgy 113, 79-85 (2012)

31. Rzelewska, M., Wiśniewski, M., Regel-Rosocka, M.: Effect of composition and ageing of chloride solutions on extraction of $\mathrm{Rh}(\mathrm{III})$ and $\mathrm{Ru}(\mathrm{III})$ with phosphonium ionic liquids Cyphos IL 101 and IL 104. Sep. Sci. Technol. 53, 1249-1260 (2018)

32. Rzelewska-Piekut, M., Regel-Rosocka, M.: Separation of Pt(IV), Pd(II), Ru(III) and Rh(III) from model chloride solutions by liquid-liquid extraction with phosphonium ionic liquids. Sep. Purif. Technol. 212, 791-801 (2019)

33. Strojanowic, A., Kogeling, D., Fisher, L., Hann, S., Galanski, M., Groessl, M., Krachler, R., Keppler, B.K.: Phosphonium and ammonium ionic liquids with aromatic anions: synthesis, properties, and platinum extraction. Aust. J. Chem. 63, 511-524 (2010)

34. Lee, J.M.: Extraction of noble metal ions from aqueous solution by ionic liquids. Fluid Phase Equilib. 319, 30-36 (2012)

35. Papaiconomou, N., Lee, J.M., Salminen, J., von Stosch, J., Prausnitz, J.M.: Selective extraction of copper, mercury, silver and palladium ions from water using hydrophobic ionic liquids. Ind. Eng. Chem. Res. 47, 5080-5086 (2008)

36. Tong, Y., Wang, Ch, Li, J., Yang, Y.: Extraction mechanism, behavior and stripping of Pd(II) by pyridinium-based ionic liquid from hydrochloric acid medium. Hydrometallurgy 147-148, 164-169 (2014)

37. Saski, K., Takao, K., Suzuki, T., Mori, T., Arai, T., Ikeda, Y.: Extraction of Pd(II), Rh(III) and Ru(III) from $\mathrm{HNO}_{3}$ aqueous solution to betainium bis(tri-fluaromethanesulfonyl)imide ionic liquid. Dalton Trans. 43, 5648-5651 (2014)

38. Pan, L., Zhang, Z.-D.: Solvent extraction and separation of palladium(II) and platinum(IV) from hydrochloric acid medium with dibutyl sulfoxide. Miner. Eng. 22, 1271-1276 (2009)

39. Pan, L., Gu, G.B., Wang, F.W., Wei, Y.-J.: Dibutyl sulfide: synthesis, Pd, Pt extraction and separation studies. Chinese J. Inorg. Chem. 24, 520-526 (2008)

40. Zhu, P., Gu, G.B., Qu, Z., Huang, Y., Yao, W.: The pilot test of Pt-Pd and Pt-Rh feeds extracted and separated with new sulfoxide extractant. Rare Met. 25, 99-105 (2006)

41. Szczepanska, I., Borowiak-Resterna, A., Wisniewski, M.: New pyridinecarboxamides for rapid extraction of palladium from acidic chloride media. Hydrometallurgy 68, 159-170 (2003)

42. Nikoloski, A.N., Ang, K.L.: Review of the application of ion exchange resins for the recovery of platinumgroup metals from hydrochloric acid solution. Miner. Process. Extr. Metall. Rev. 35, 369-389 (2014)

43. Puigdomenech, I.: Medusa (Make Equilibrium Diagrams Using Sopisticated Algorithms). Royal Institute of Technology, Sweden (2009) 
44. Yamaguma, R., Yamashita, A., Kawakita, H., Miyajima, T., Takemura, C., Ohto, K., Iwachido, N.: Selective extraction of precious metal ions with novel trident molecules containing pyridyl groups. Sep. Sci. Technol. 47(9), 1303-1309 (2012)

45. Mellah, A., Benachour, D.: The solvent extraction of zinc, cadmium and chromium from phosphoric acid solutions by tri- $n$-butyl phosphate in kerosene diluent. Sep. Purif. Technol. 56, 220-224 (2007)

Publisher's Note Springer Nature remains neutral with regard to jurisdictional claims in published maps and institutional affiliations. 